\title{
Endoscopic retrograde cholangiopancreatography in children
}

\author{
P B COTTON AND N J LAAGE
}

Gastrointestinal Unit, Middlesex Hospital, London

SUMMARY Gastroduodenoscopy and retrograde cholangiopancreatography has been performed on 25 occasions in 20 children aged between 7 and 16. Radiographs of the clinically relevant duct or ducts were achieved in $96 \%$ of attempts, with no complications. The diagnostic information proved useful clinically; in particular it provided a precise map if biliary or pancreatic surgery was being contemplated. Several unexpected congenital duct anomalies were found. This and other recent reports, particularly from Germany, indicate that endoscopic retrograde cholangiopancreatography deserves greater application in children, and can also be used in babies.

Fibreoptic duodenoscopy with cannulation of the papilla of Vater for endoscopic retrograde cholangiography and pancreatography (ERCP) is a wellknown diagnostic (and therapeutic) procedure in adult gastroenterology, ${ }^{1}$ but it has seldom been used in children; by 1980 only 30 cases had been reported in the English language. ${ }^{2-10}$ Perhaps this is because biliary and pancreatic diseases are fairly rare in infancy and childhood, but it also reflects a lack of appreciation by gastroenterologists and paediatricians alike of the possibility of applying the technique in children. For this reason, we report our experience of 25 ERCP examinations in 20 children aged 16 years and younger.

\section{Patients and methods}

Patients. There were 12 girls and 8 boys whose ages ranged from 7 to 16 (Fig. 1); 4 children were below the 3 rd centile for height and weight. The spectrum of presenting clinical problems is shown in the Table. Three children were jaundiced, one child had recurrent cholangitis after choledochoduodenostomy, and 2 suffered attacks of biliary-type pain with previous negative investigations. Eight children had recurrent pancreatitis, and 2 had sustained pancreatic trauma. Three other children had recurrent attacks of pain believed to be of pancreatic origin, and one had pancreatic or biliary-type pain after surgery.

Examinations were repeated in the one child in whom pancreatography initially failed, and in 2 of the children with biliary tract problems to assess progress and response to surgery. Three examinations

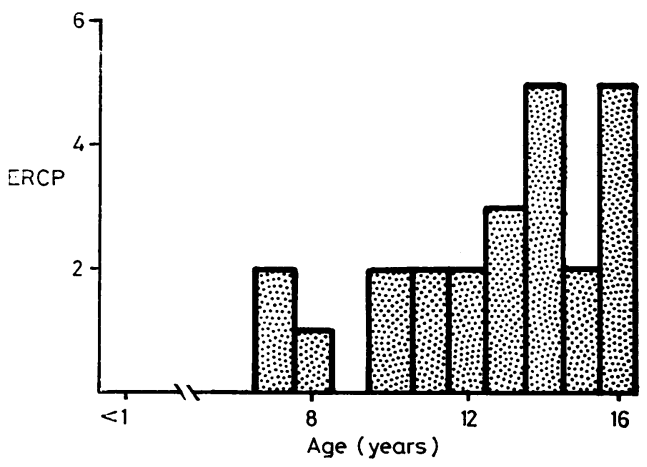

Fig. 1 Ages at which the children were examined.

were performed in one child in attempts to remove a pancreatic duct stone.

Techniques of examination. All children were admitted to hospital for the procedure which took place in the department of radiology. Thirteen children had general anaesthetics, all of whom, with the exception of one, were aged less than 13 years; the others were examined using intravenous injections of diazepam and pethidine. Antibiotics were not given routinely.

Twenty of the procedures were undertaken with standard Olympus JFB2 and JFB3 adult duodenoscopes; an experimental paediatric side viewing duodenoscope (external diameter $8 \mathrm{~mm}$ ) was used in Cases 17-20. Cannulation of the papilla of Vater proved easier with tapered-tip catheters. 
Table Clinical details and results of investigations

\begin{tabular}{|c|c|c|c|c|}
\hline $\begin{array}{l}\text { Presenting clinical } \\
\text { problem }\end{array}$ & Case & Ultrasound & $E R C P$ & Other \\
\hline Pain? biliary & $\begin{array}{l}1 \\
2\end{array}$ & $\begin{array}{l}\text { Normal } \\
\text { Normal }\end{array}$ & $\begin{array}{l}\text { Normal } \\
\text { Normal }\end{array}$ & \multirow{11}{*}{$\begin{array}{l}\text { PTC failed. Succeeded later } \\
\text { PTC failed } \\
\text { PTC failed }\end{array}$} \\
\hline \multirow[t]{2}{*}{ Jaundice } & 3 & Not done & $\begin{array}{l}\text { Hepatic duct stricture, pancreas } \\
\text { divisum }\end{array}$ & \\
\hline & $\begin{array}{l}4 \\
5\end{array}$ & $\begin{array}{l}\text { Not done } \\
\text { Gallbladder stones;? duct stones }\end{array}$ & $\begin{array}{l}\text { Hapatic duct stricture } \\
\text { Gallbladder stones; clear duct }\end{array}$ & \\
\hline Cholangitis & 6 & Normal & Stenosed choledochoduodenostomy & \\
\hline $\begin{array}{l}\text { Pain; ?biliary or } \\
\text { pancreatic }\end{array}$ & 7 & Not done & $\begin{array}{l}\text { Patent choledochoduodenostomy; } \\
\text { Bile duct stricture. } \\
\text { ERP failed; succeeded later }\end{array}$ & \\
\hline Pain; ?pancreatic & $\begin{array}{r}8 \\
9 \\
10\end{array}$ & $\begin{array}{l}\text { Not done } \\
\text { Normal } \\
\text { Normal }\end{array}$ & Normal & \\
\hline Pancreatitis & $\begin{array}{l}11 \\
12\end{array}$ & & Normal & \\
\hline & $\begin{array}{l}13 \\
14 \\
15\end{array}$ & Normal & $\begin{array}{l}\text { Pancreatitis } \\
\text { Pancreas divisum }\end{array}$ & \\
\hline & 16 & Abnormal & & \\
\hline & $\begin{array}{l}17 \\
18\end{array}$ & $\begin{array}{l}\text { Normal } \\
\text { Mass }\end{array}$ & $\begin{array}{l}\text { Pancreatic stone; duct dilated } \\
\text { Mass with dilated duct }\end{array}$ & \\
\hline Pancreatic trauma & $\begin{array}{l}19 \\
20\end{array}$ & $\begin{array}{l}\text { Cyst } \\
\text { Mass }\end{array}$ & Obstructed duct & \\
\hline
\end{tabular}

PTC $=$ percutaneous transhepatic cholangiography.

\section{Results}

Diagnostic examinations were completed within 30 minutes in each patient, and there were no complications. The papilla was seen and cannulated in each child, with successful opacification of the clinically relevant duct or ducts in $24(96 \%)$ of the 25 examinations. There were no failures of cholangiography, but pancreatography failed initially in one child in whom it was intended to opacify both duct systems; a second attempt was successful. Four children proved to have the congenital anomaly of pancreas divisum, in which the main pancreatic duct drains only through the accessory papilla of Vater.

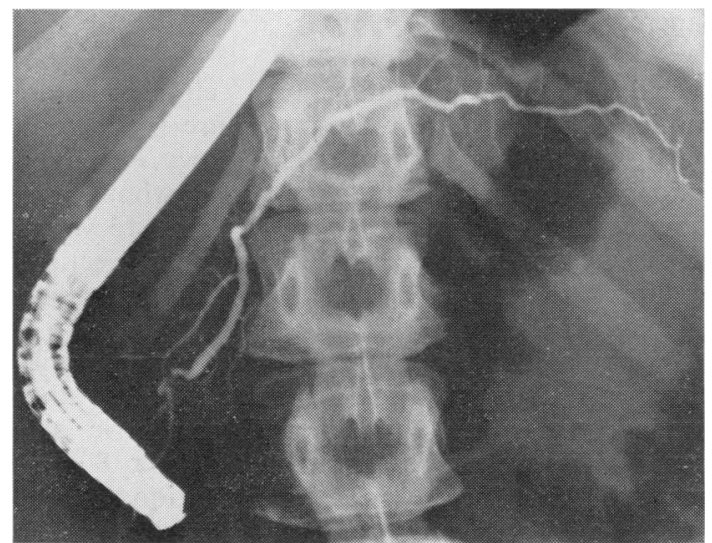

Fig. 2 Normal endoscopic pancreatogram.
Endoscopic cannulation of the accessory papilla was achieved in all 4 cases (Fig. 3).

The gastroduodenoscopy inherent in ERCP revealed diagnostic information in only one child -8 stenosis of a previous surgical choledochos duodenostomy. Radiological findings are sum marised in the Table and shown in Figs 2 to 5.

Normal duct sizes in children. The size of the normal pancreatic duct (for example Fig. 2) was measured in five children aged between 7 and 16. The diameter in the head ranged from 1.4 to $2.1 \mathrm{~mm}$, and in the body from 1.1 to $1.9 \mathrm{~mm}$. Normal cholangiograms were obtained in 7 children aged between 7 and 16 years. The diameter of the common bile duct just below the entry of the cystic duct varied from $2 \cdot 1$ to $4.9 \mathrm{~mm}$ (all measurements corrected for radiographic magnification).

Results of related diagnostic techniques. Three of the 4 children with jaundice or cholangitis had previously undergone failed percutaneous cholangiograms; the examination was successful subsequently in one. Ultrasound scanning had been performed before ERCP in 15 of the 20 children. In one jaundiced child the scan had shown stones in the gallbladder and had raised the possibility of a further stone in the distal common bile duct; ERCP confirmed the gallbladder stones, but excluded duct stones (Fig. 4). Ultrasonography showed no evidence of bile duct dilatation in the patient suffering recurrent cholangitis after choledochoduodenostomy; ERCP showed stenosis of the stoma. 


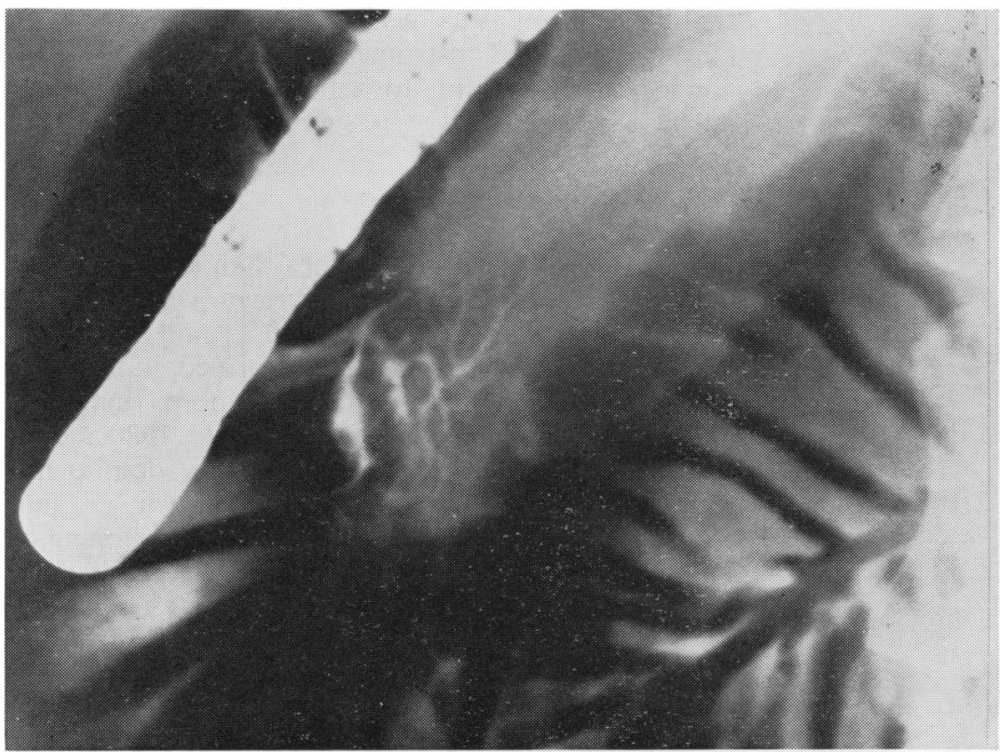

Fig. 3a Cannulation of the main papilla showing only the ventral pancreas in a child with pancreas divisum.

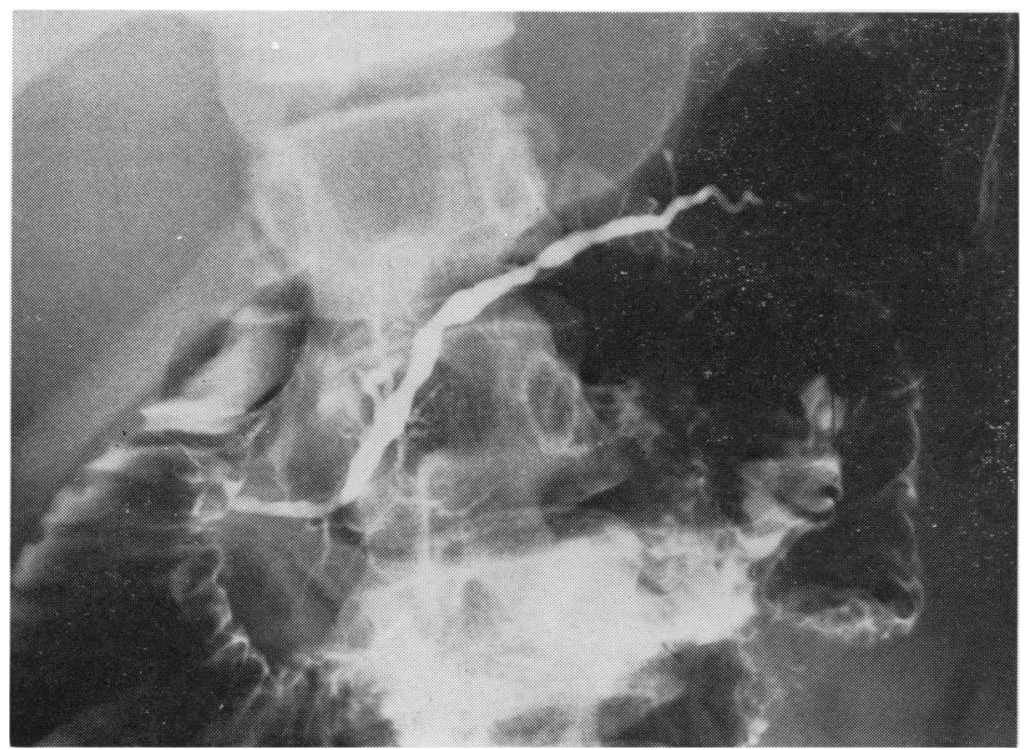

Fig. 3b Same child. Cannulation of the accessory papilla has outlined the remainder of the pancreas via Santorini's duct; no connection with the ventral pancreas.

Pancreatic ultrasonography was normal in 2 children with suspected pancreatic pain; each had normal pancreatograms. There were 10 children with recurrent pancreatitis or pancreatic trauma. Scans were normal in the 2 children with normal pancreatograms, but were abnormal in only 4 of the 8 with abnormal ductograms.
Attempted endoscopic treatment of a pancreatic stone. One child had begun to have attacks of pancreatitis at age 7. At 12 years, ERCP showed an irregular but undilated duct with obstruction near the tail, at the site of a previous pseudocyst. By age 16, she had a stone in the pancreatic duct near the papilla, with upstream duct dilatation. Endoscopic diathermy 
Fig. 4 Cholangiogram showing gallbladder stones (arrowed).

sphincterotomy was performed at the pancreatic duct orifice, and instruments were passed into the duct in vain attempts to remove the stone; surgery proved successful.

\section{Discussion}

ERCP was first described more than a decade ago. The technique is now widely known, with cannulation success rates of at least $90 \%$, and few complications. ${ }^{1}$ ERCP is being performed in at least 100 hospitals in the UK, and more than 600 examinations were performed here in 1980 alone. Demands for ERCP continue to rise, despite the development of other techniques-such as fine needle percutaneous transhepatic cholangiography, ${ }^{11} 12$ ultrasound ${ }^{1314}$ and computerised tomography. ${ }^{15}$

This small series shows that ERCP can be performed in children and that it has a high success rate without complications. Single case reports and smaller series have been described from Japan, ${ }^{4}$ USA, ${ }^{2} 10$ Norway, ${ }^{3}$ South Africa, ${ }^{57}$ Italy, ${ }^{8}$ and Germany. ${ }^{6}$ Several groups presented abstracts to the European Congress of Gastrointestinal Endoscopy in Hamburg in 1980 and there have been more recent publications in German.16-20 Despite̊ this, total world experience probably does not exceed 100 procedures, and most of these have beem in children over age 10 years. The youngest child in our series was aged 7 years, since none younger was referred. However, Waye has achieved ERCP in 2 infants aged only 4 months. ${ }^{29}$ Like others, he used

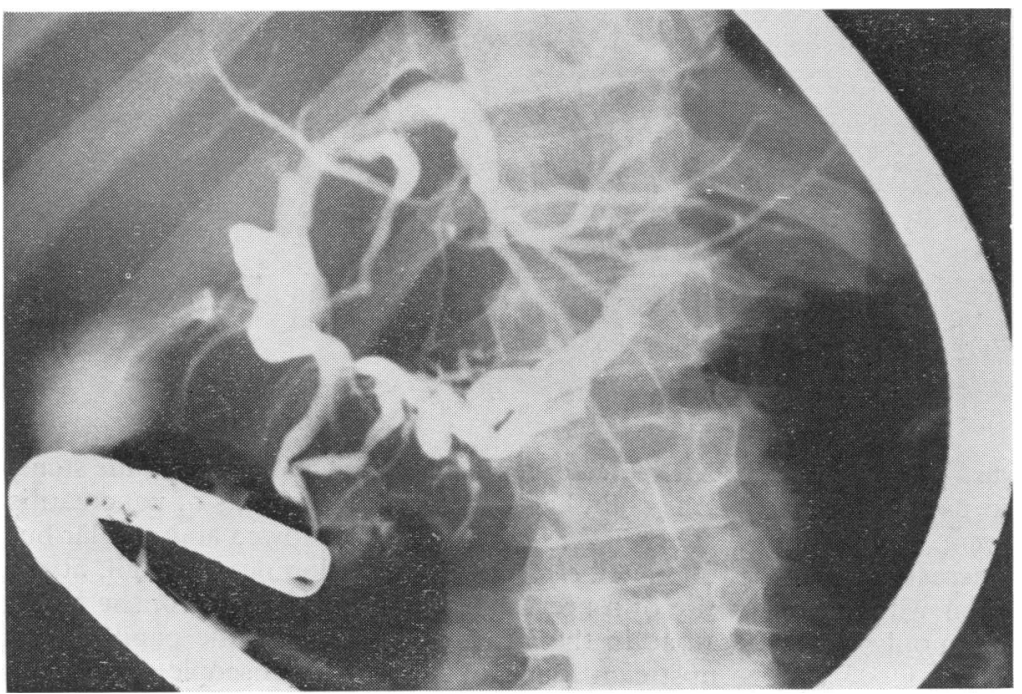

Fig. 5 Mass in the head of the pancreas, probably the result of trauma, with upstream dilatation of both pancreatic and biliary systems. 
adult duodenoscopes, and it is likely that the procedure would be simpler with paediatric instruments. Our preliminary evaluation of such an instrument is encouraging.

Most groups have used general anaesthesia, particularly in children under age 10 years. General anaesthesia complicates the procedure technically, and recent reports indicate that ERCP can be performed satisfactorily under sedation, even in younger children.

ERCP is an invasive technique, and many complications have been reported ; ${ }^{121}$ cholangitis and pancreatitis are the most feared. Such risks can be lessened so that the chance of complications is slight in expert hands; we have had no complications of diagnostic ERCP in the last 1000 examinations. Acute pancreatitis and pancreatic necrosis has been described after ERCP in an 8-year old girl with pancreatic cysts. ${ }^{6}$ Cysts and pseudocysts are a contraindication to ERCP: any patient in whom a cyst is suspected should have an ultrasound scan; in our department pancreatography is then only performed as an immediate preoperative procedure.

It is clear from this report that ERCP can usefully be applied in children; however its clinical role cannot be established from the small experience to date. Children with biliary problems are normally well served by established techniques of cholecystography, ultrasound scanning, and percutaneous transhepatic cholangiography. ${ }^{12}$ However, percutaneous transhepatic cholangiography may sometimes fail (as in $\mathbf{3}$ of our patients), particularly in very small children with non-dilated ducts. Percutaneous transhepatic cholangiography is also contraindicated in patients with coagulation problems. Endoscopic cholangiography deserves further evaluation in such cases, and may be particularly appropriate with miniaturised instruments in the neonatal period.

The most common pancreatic disease in children, fibrocystic disease, can generally be diagnosed without the need for imaging techniques. Ultrasound scanning has made a major impact on pancreatic and liver diagnosis in adults, and is likely to make an increasing contribution in children. It is also probable that simplified exocrine function tests will achieve a role. At present, the relationship between scans, function tests, and pancreatography have yet to be established. From this series and from our experience on adults, ${ }^{1415}$ it is clear that duct radiographs can sometimes provide a diagnosis if scans are negative, but the main role of pancreatography is to provide a precise map if pancreatic surgery is being contemplated. ${ }^{22}$ There is increasing recognition of the importance of congenital pancreatic duct anomalies, which can only be demonstrated by ERCP, as in 4 children in this series. Failure of fusion of the dorsal and ventral embryological parts of the pancreas (pancreas divisum) was found in $25 \%$ of adults with pancreatitis unrelated to gallstones or alcohol abuse. ${ }^{23} \mathrm{~A}$ significant advantage of ERCP is that cholangiography and pancreatography may both be relevant to the clinical problem as in children with choledochal cysts associated with a long common channel. Trauma is one of the most common causes of pancreatitis in children. Most of these injuries can be recognised in the acute phase by standard clinical techniques and ultrasound scanning, but definitive surgery may be facilitated by preoperative pancreatography. ${ }^{24}$

ERCP can be performed in children with relative ease. Its clinical contribution will only be established by much wider application, which current experience would encourage.

\section{References}

1 Cotton P B. ERCP. Gut 1977; 18: 316-41.

2 Waye J D. Endoscopic retrograde cholangiopancreatography in the infant. Am J Gastroenterol 1976; 65: 461-3.

3 Alwmark A, Jonson G, Mattsson K. Chronic relapsing pancreatitis in a child-endoscopic diagnosis. Acta Chir Scand 1977; 143: 253-5.

4 Urakami Y, Seki H, Kishi S. Endoscopic retrograde cholangiopancreatography (ERCP) performed in children. Endoscopy 1977; 9: 86-91.

5 Van der Spuy S. Biliary ascariasis-endoscopic aspects. $S$ Afr Med J 1978; 53: 1030-3.

- Riemann J F, Koch H. Endoscopy of the biliary tract and the pancreas in children. Endoscopy 1978; 10: 166-72.

7 Van der Spuy S. Endoscopic retrograde cholangiopancreatography (ERCP) in children. Endoscopy 1978; 10: $173-5$.

8 Vantini I, Piubello W, Ederle A, Adamo S, Cavallini G, Scuro L A. Hereditary pancreatitis: morphological pictures (ERCP) in the youngest member of a family. Acta Hepatogastroenterol (Stuttg) 1979; 26: 253-6.

9 Lebwohl O, Waye J D. Endoscopic retrograde cholangiopancreatography in the diagnosis of extra-hepatic biliary atresia. Am J Dis Child 1979; 133: 647-9.

10 Filston H C, McLeod M E, Bolman R M, Jones R S. Improved management of pancreatic lesions in children aided by ERCP.J Pediatr Surg 1980; 15: 121-8.

11 Elias E, Hamlyn A N, Jain S, Long R, Summerfield J A, Dick R, Sherlock $S$. A randomized trial of percutaneous transhepatic cholangiography versus endoscopic retrograde cholangiography for bile duct visualization in cholestasis (abstract). Gut 1975; 16: 831.

12 Howard E R, Nunnerley H B. Percutaneous cholangiography in prolonged jaundice of childhood. $J$ R Soc Med $1979 ; 72$ : 495-502.

13 Lees W R, Vallon A G, Denyer M E, Vahl S P, Cotton P B. Prospective study of ultrasonography in chronic pancreatic disease. $\mathrm{Br}$ Med J 1979; i: 162-4.

14 Cotton $\mathbf{P}$ B, Lees W R, Vallon A G, Cottone $M$, Croker J R, Chapman M. Gray-scale ultrasonography and endoscopic pancreatography in pancreatic diagnosis. Radiology 1980; 134: 453-9.

15 Cotton P B, Denyer M E, Kreel L, Husband J, Meire H B, Lees W. Comparative clinical impact of endoscopic 
pancreatography, grey-scale ultrasonography, and computed tomography (EMI scanning) in pancreatic disease: preliminary report. Gut $1978 ; 19$ : 679-84.

16 Becker M, Miederer S E, Emons D, Rotthauwe H W. Endoskopisch-retrograde Cholangio-Pankreatikographie im Kindesalter. Dtsch Med Wochenschr 1980; 105: $1055-60$

17 Classen M. Postbulbare Duodenoskopie und endoskopisch-retrograde Cholangio-Pancreaticographie (ERCP). In: Frühmorgen $\mathrm{P}$, Classen $\mathrm{M}$, eds. Endoskopie und Biopsie in der Gastroenterologie. Berlin: Springer, 1979.

18 Cremer N, Cadranel S, Rodesch P, Cremer M. Pediatric gastrointestinal fiberendoscopy. In: Eklof O, ed. Current concepts in pediatric radiology. Berlin: Springer, 1977: 32.

19 Huchzermeyer H, Burdelski M, Gebel M. Diagnostische Bedeutung der endoskopischen retrograden CholangioPankreatikografie (ERCP) und der perkutanen transhepatischen Feinnadelcholangiografie (PTC) beim Cholestase-Syndrom in Kindes-und Jungendalter. Leber Magen Darm 1979; 9: 60-4.

20 Manegold B C, Joppich J. Laparoskopie und endos- kopisch retrograde Cholangiopankreatikographie (ERCP) im Kindesalter. $Z$ Kinderchir 1979; Supplement 27, 125.

21 Bilbao M K, Dotter C T, Lee T G, Katon R M. Complications of endoscopic retrograde cholangiopancreatography (ERCP). A study of 10000 cases. Gastroenterology 1976; 70: 314-20.

22 Cotton P B, Beales J S M. Endoscopic pancreatography in the management of relapsing acute pancreatitis. $\mathrm{Br} \mathrm{Med} \mathrm{J}$ 1974 ; i: $608-11$.

${ }^{23}$ Cotton P B. Congenital anomaly of pancreas divisum as cause of obstructive pain and pancreatitis. Gut $1980 ; 21$ : 105-14.

24 Vallon A G, Lees W R, Cotton P B. Grey-scale ultrasonography and endoscopic pancreatography after pancreatic trauma. BrJ Surg 1979; 66: 169-72.

Correspondence to $\mathrm{Dr}$ P B Cotton, Middlesex Hospital, Mortimer Street, London W1N 8AA.

Received 10 March 1981 